\title{
Nuestra época en clave estética: estetización generalizada y nuevas artes
}

\author{
MATEU CABOT RAMIS \\ Universidad de las Islas Baleares
}

NUESTRO MUNDO, CONSIDERADO DESDE la estética filosófica, puede caracterizarse con las categorías «estetización generalizada» y «nuevas tecnologías». Dos categorías que permiten profundizar en la comprensión de fenómenos de nuestra cultura actual. Este trabajo pretende ser una contribución a la construcción teórica de dichas categorías. Procederemos, primero, a analizar cada una de las dos categorías con la intención de aclarar su significado y la red conceptual en que están entretejidas, para después valorar algunos de los cambios conceptuales que de este análisis surgen inmediatamente.

\section{SOBRE EL TÉRMINO «ESTETIZACIÓN».}

El término «estetización» es ambiguo y polisémico. Ante todo porque ni siquiera ha habido tiempo de incorporarlo al diccionario de la Real Academia Española, cuando menos hasta la $22^{a}$ edición (2001) y, por vía prescriptiva, fijar su significado. Además, al ser su uso eminentemente teórico, prácticamente circunscrito a los departamentos universitarios implicados, ha sido utilizado en discursos estructural e intencionalmente muy dispares con la complejidad semántica que ello implica. El aire de familia de tantos significados, sin embargo, parece más o menos claro.

Además, en ocasiones podemos observar que el uso del término lleva aparejado una difusa calificación moral. Es cuando se usa en el tono y sentido despectivo equivalentes al que se usa, también en ocasiones, el término «barroco». En estos casos los términos «decadente» $\mathrm{y}$ «degenerado» servirían para la misma función edificante pretendida.

Para complicar más las cosas, el significado difuso del término «estetización» aparece en ocasiones encarnado en otros términos. Como ejemplo vale el reciente libro de Yves Michaud, El arte en estado gaseoso. Ensayo sobre el 
triunfo de la estética (2003), en el que la expresión «triunfo de la estética» en usada en el mismo sentido que muchos otros usan «estetización».

Desde una posición académica o del «mundo del arte» (en el sentido que le da Arthur Danto) ${ }^{1}$ lo que se llama «estetización» parece significar que el arte contemporáneo, a diferencia del moderno, ya no produce necesariamente una «obra», puesto que el arte puede ser procesual, ambiental, conceptual, minimalista, ... y sensibilizarse no en objetos, sino en acciones, interacciones o casualidades. Este disolverse, en el sentido de «no concretarse en obras definidas y concretas», es concebido como un vaporizarse que impregna todos los objetos y hechos de la vida de las sociedades actuales.

El autor antes citado inicia con las siguientes palabras su ensayo de etnografía del arte contemporáneo: «Este mundo es exageradamente bello. Bellos son los productos empacados, la ropa de marca con sus logotipos estilizados, los cuerpos reconstruidos, remodelados o rejuvenecidos por la cirugía plástica, los rostros maquillados, tratados o lifteados, los piercings y los tatuajes personalizados, el ambiente protegido y conservado, el marco de vida adornado por las invenciones del diseño, los equipos militares con su aspecto cubo-futurista, los uniformes rediseñados tipo constructivista o ninja, la comida mix en platos decorados con salpicaduras artística a no ser que de manera más modesta sea empaquetada en bolsas multicolores en los supermercados, como las paletas Chupa Chup. Hasta los cadáveres son bellos cuidadosamente envueltos en sus fundas de plástico y alineados al pie de las ambulancias. Si algo no es bello, tiene que serlo. La belleza reina. De todas maneras, se volvió un imperativo: ¡Qué seas bello! O, por lo menos, ¡ahórranos tu fealdad!» ${ }^{2}$. Esto es: al perder el arte su apoyo objetual, los objetos se han vuelto arte. $\mathrm{O}$ al menos han adquirido rasgos propios y característicos del Arte: ser venerados, admirados, estudiados, comprados, disfrutados. El Arte se evapora y el mundo se vuelve estético ${ }^{3}$.

Iniciemos el camino para intentar definir más el término. Más concretamente, ¿a qué fenómenos de la vida social e individual se apunta con el término «estetización»? Dicho de otra manera: ¿cuál es su referente?

Se alude, en primer lugar, a «la belleza de este mundo». Mantengamos la carga irónica de citar esta expresión y enumeremos los siguientes hechos contemporáneos que aparecen mencionados en la mayoría de análisis del fenómeno como componentes necesarios para este proceso de estetización: (a) La definitiva institucionalización del Arte ocurrida en la segunda mitad del siglo XX, sea directamente por vía del patronazgo cultural del Estado, sea por la

1 A. Danto, «The Artworld», en: The Journal of Philosophy, 61 (1964), pp. 571-584.

2 Y. Michaud, El arte en estado gaseoso, tr. L. le Bouhellec, México: FCE, 2007, p. 9.

3 Para entender del todo la fórmula es necesario precisar que Michaud entiende la estética como la «rama de la filosofía tratando del arte y su experiencia», p. 89. 
conexión administrativa entre ámbitos distintos de la vida social, como es, por ejemplo, la exención fiscal debido al financiamiento particular de actividades culturales, sea por la regulación del sector desde los grandes museos y centros, sea por la codificación de la crítica mediantes las publicaciones establecidas y subvencionadas, sea por el carácter representacional -nacional de las bienales y otras ferias, etc. (b) La pérdida del carácter suntuario de los «ornamentos» que pueblan nuestra vida, de tal forma que ya puede considerarse no sólo como socialmente aceptable, sino incluso necesaria socialmente, la atención a la apariencia del cuerpo, a la apariencia o «imagen pública» de la propia vida personal, de las relaciones sociales que establecemos, etc. Con todo ello se han vuelto familiares expresiones como «culto al cuerpo» o bodybuilding o «cirugía estética» y se vuelvan tópicos los términos «look», «diseño», «cool», etc. La inflación de términos compuestos con la raíz «estétic-» en el lenguaje cotidiano o la omnipresencia de la industria cosmética en la publicidad sólo son consecuencias de ello, no la causa. (c) La potenciación técnica de los medios de transmisión de información, fundamentalmente visual, consiguiendo un grado de penetración en la realidad y en la vida cotidiana de los individuos mayor que en cualquier otro momento histórico. Ejemplos serían la transmisión en directo de los atentados terroristas de las Torres Gemelas o el inicio de una guerra lejana o que mil millones de personas repartidas por todo el mundo estén viendo el mismo partido de fútbol. Efectos serían la adecuación de las costumbres - incluso íntimas-, de los modos de vida en definitiva, a los modelos transmitidos por esos mismos medios (tomando, por tanto, por real lo que ellos transmiten). (d) La rápida substitución colectiva de cualquier estándar (moda) de aspecto personal (cuerpo, atuendos, accesorios, vehículo de transporte, hogar, etc.) y, a la vez, la presentación de este transitorio y fugitivo estándar con los rasgos de la permanencia o ahistoricidad, para lo cual es necesario que tal estándar esté permanentemente en consideración de la opinión pública. (e) El revestimiento con los caracteres más aparenciales (más visuales) de amplios ámbitos de la vida humana que, en principio, se regían por normas que no los contenían. Esto puede observarse incluso en la política. En este caso se manifiesta, por ejemplo, en que en la dirección de las campañas electorales figuren publicitarios y que se busque el programa más «vendible» al consumidor votante mediante el candidato más «fotogénico», acabando todo ello en la importancia política del formato, fecha, lugar y orden de intervención en el o los debates televisivos que toda campaña debe tener. (f) La incorporación del término «estética» como nombre «científico» o serio en lugar del término «bello», cuando se ha hecho evidente ya que «bello» quiere decir siempre «bello según un canon de belleza histórica y socialmente determinado», con la subsiguiente saturación del lenguaje cotidiano con el término y sus derivados.

Podríamos insistir en ello. Como han señalado algunos no es sólo que todo deba ser bello (según un criterio de belleza definido a partir de una particular 
situación socio-histórica), sino que el todo de la Realidad en la que juega el individuo y los grupos sociales a los que pertenece tienen en cuenta, muy en cuenta, la apariencia, el modo de aparecer. Somos conscientes de que está pendiente rescatar el término «apariencia» del juego de lenguaje «apariencia vs. realidad», rescoldo último del platonismo contra el que luchó Nietzsche. En este rescate dejaríamos atrás, deberíamos dejar atrás, todo dualismo para tomar una visión más realista, más acorde con las complejidades del Lebenswelt contemporáneo: la existencia de una multiplicidad de niveles o dimensiones de la realidad, que se entrecruzan, niveles entre los cuales vamos circulando constantemente y, por tanto, priorizando y haciéndolos el punto de partida de nuestro pensar, percibir, hablar, etc.

Una dificultad que encontramos en el análisis de los fenómenos anteriores es que, en ocasiones, al tratar ese mundo la teoría parece contagiarse por el ambiente flou o soft en que se mueven los acontecimientos de ese mundo. En estos casos se entiende «apariencia» en el sentido de falta de consistencia o de substancia, en un sentido más gastronómico que filosófico pero igualmente dependiente de la dualidad antes citada. Remarcamos esta tendencia pues tiene graves consecuencias ya que en ocasiones puede llevar a una renuncia teórica: el achacar la estetización generalizada a una suerte de moda pasajera, a una tendencia que pasará, como todas las tendencias y que, por tanto, no tiene la importancia para convertirse en objeto de análisis y reflexión teórica se está renunciando al análisis de una parte considerable de la vida contemporánea, la más substancial.

Las distintas modas, todas ellas, las incompatibles entre sí incluso, comparten el pertenecer al fenómeno «Moda». Desde los primeros análisis teóricos de la moda, ese fenómeno tan característico de nuestras sociedades, quedó claro que era un fenómeno inherente a las sociedades capitalistas de masas y de consumo ${ }^{4}$. Desde otros lugares también desde un principio se le atribuyó una lógica alocada de funcionamiento, caprichosa y azarosa. Pero esto no es más que ideología pura y dura, como cuando se dice «jugar en Bolsa», pretendiendo que el azar reina en ese ámbito cuando, en realidad, imperan las férreas leyes del desarrollo capitalista. No es moda en este sentido ideológico de «azaroso, casi irracional», sí lo es en el sentido de fenómeno ligado estructuralmente a una fase de desarrollo del capitalismo. El momento de estetización generalizada en que está inmerso el mundo en que vivimos va más allá de la conexión entre

4 Uno de los primeros en percatarse, casi en sus orígenes, de la importancia del fenómeno fue el sociólogo Georg Simmel (1858-1918), que en 1905 publicó «La moda». No obstante, este primer ensayo acentúa en el fenómeno el carácter de interacción social entre individuos, más que el de estructura del intercambio capitalista, del mercado. Para el artículo, vid. G. Simmel, Cultura femenina y otros ensayos, tr. G. Dieterich, Barcelona: Alba, 1999, pp. 35-71. 
Culto-a-la-apariencia y Huída-del-arte-desde-la-apariencia-hacia-el-efecto. La desmaterialización del objeto artístico ${ }^{5}$ la vaporización del arte ${ }^{6}$ son sólo dos formulaciones de las consecuencias del proceso, pero no la causa de nada.

Sin pretender una relación exhaustiva y/o sistemática, por otra parte imposible, pueden, y deben, explicitarse aquellos elementos teóricos que, pertenecientes a la historia de las ideas o del arte, tienen algún tipo de participación en la emergencia de la situación de estetización generalizada: (a) La o las crisis de la razón, de los valores, de fundamentación, de legitimación, en cuanto son el resultado de todo un siglo de someter a crítica la racionalidad dominante y sus productos. Fruto de este proceso de autocrítica de la razón sería la ausencia en este momento de un criterio firme, unívoco y único de lo que es racional, verdadero, bueno y útil, lo cual provoca la crisis del paradigma cultural dominante sin la aparición de un substituto y, de esta manera, que por todo el ámbito del saber se extiendan múltiples propuestas no siempre comparables, múltiples criterios de racionalidad, múltiples formas de vida y, también, múltiples criterios estéticos. Es decir, una multiplicidad no reducible a unidad. Esto, en tono más despectivo que crítico, suele llamarse «relativismo». (b) La crítica llevada a término durante todo el siglo $\mathrm{XX}$ a los grandes sistemas filosóficos (y también a los paradigmas culturales) se ha movido en la dirección de disolver algunas categorías, conceptos y teorías caracterizadas todas ellas por ser estáticas, rígidas, basadas en una concepción de los conceptos como algo fijo, unívocamente definido, construidas, casi podría decirse, según el modelo de la ciencia dominante en el siglo XIX, una concepción positivista de la ciencia. Lo cual provoca no solo la ausencia de un gran sistema de referencia con pretensión de solidez y sistematicidad, sino también la desconfianza y el descrédito de este tipo de marco de referencia. (c) La pérdida final de peso de las «grandes narrativas», es decir, de los discursos que desde dentro de la historia pretenden una explicación (o interpretación) de la propia historia para darle un «sentido» a los hechos y las acciones del presente en el que vive el que cuenta la historia. Un ejemplo paradigmático sería la concepción ilustrada de la historia universal, que es vista como un progreso indefinido hacia lo mejor, de dominio de la naturaleza tanto la externa como la interna de los hombres. La caída de este modelo explicativo y la ausencia de una alternativa del mismo tipo, por las razone expuestas en el punto anterior, siembra el desconcierto ante un supuesto vacío explicativo que, a su vez, hace que el «anything goes» se tome como problema y peligro y no como posibilidad. (d) La propia dinámica del arte, y también de la estética filosófica, que ha dejado atrás la época de los manifiestos, parece que definitivamente, por ahora, para entrar en otra en la que los presupuestos están

5 Cf. L. R. Lippard, Seis años: la desmaterialización del objeto artístico de 1966 a 1972, tr. M. L. Rodríguez, Madrid: Akal, 2004.

6 Y. Michaud, op. cit. 
más definidos por la libertad formal e ideológica. Esto es: que los presupuestos y procedimientos se definen inmanentemente a la propia obra o acción artística, sin apenas necesidad de referentes ni criterios externos a ella.

A pesar de la existencia de éstas razones, y aún hay más, existe también la tendencia a disolverlo todo en la confusión que se supone intrínseca a la situación de «estetización generalizada». En este caso se produce un sigiloso corrimiento del centro de gravedad del tema desde el terreno del análisis y juicio filosófico-estético al sociológico-ético. Con ello no afirmamos que existan disciplinas estancas y autárquicas, pues cualquier objeto es motivo de múltiples perspectivas, sino que los métodos, procedimientos, criterios, etc. han de mantenerse de forma mínimamente coherente, esto es: no puede utilizarse un método de análisis y, a la postre, aplicar unos criterios de demarcación ajenos e incluso contrarios al método seguido. En las casi siempre difíciles relaciones entre ética y estética tal vez sea éste el único criterio apodíctico que pueda darse ${ }^{7}$.

Precisamente éstos son los problemas que emergen en las valoraciones implícitas tal como suele concebirse el significado de «estetización generalizada»: flotan siempre los epítetos «moda», «efímero», «apariencia»,... en el sentido negativo de cualidades degradadas en relación a las «buenas»: consistente, eterno, verdadero-real,...Lo etéreo contra lo sólido. Pero esto ya son valoraciones éticas que introducen un elemento extraño en la consideración estética (si mantenemos el postulado ilustrado de los tres ámbitos de relación del Hombre con el Mundo). En cualquier caso podemos tratar aquí, desde la Teoría, la cuestión de las causas y las consecuencias de que exista esa sobreabundancia de belleza (cada cual que se la componga a su gusto), pero en la Sociedad seguirán rigiendo las valoraciones bueno/malo según su propio criterio. Lo que pretendemos es lo que antaño se llamaba «estudio científico», donde «ciencia» mantiene su sentido enfático como lo tenía en Hegel. A esto nos limitaremos.

Una propuesta de concreción del significado de «estetización generalizada», ya puesta en práctica en otro lugar ${ }^{8}$, podría ser la siguiente: convertir, o pretender convertir, en algo de índole estética regiones de la vida y de la realidad que, en principio, le son ajenos. «Convertir» quiere decir, en este caso, «tratar como si» las reglas o leyes que rigen el o los fenómenos en cuestión fuesen las que regulen, o parecen regular, la experiencia estética. La consecuencia es la utilización de términos, imágenes, objetivos, métodos... extraídos del ámbito de la estética

7 La literatura existente sobre esta cuestión concreta es amplia. De entrada podrían citarse los dos títulos siguientes: J. Früchtl, Ästhetische Erfahrung und moralisches Urteil, Frankfurt am Main: Suhrkamp, 1996; D. Fenner, Kunst - jenseits von Gut und Böse? Kritischer Versuch über das Verhältnis von Ästhetik und Ethik, Basel: Francke, 2000.

8 M. Cabot, Más que palabras. Estética en tiempos de cultura audiovisual, Murcia: CENDEAC, 2007, principalmente cap. 4, pp. 67-85. 
dentro de los ámbitos de la política, la moral, la sociología, pero también, y esto es lo más importante tal vez, en la vida cotidiana, en las relacione personales, en el ejercicio del poder, etc. En ocasiones este traspaso de herramientas y funcionalidades de un ámbito a otro no funciona o, simplemente, no funciona ni de acuerdo a los criterios y parámetros de ninguno de los dos ámbitos. En otras ocasiones, sin embargo, simplemente se crea con ello un nuevo objeto de estudio que viene para quedarse con nosotros. Ejemplo de esto último serían las sub-culturas de las llamadas tribus urbanas; más concreto: que algo pueda ser llamado «modo de expresión»o «vandalismo» simultánea/indiferente/mente.

Con ello, y aunque estemos inmersos en la confusión teórica que siempre provocan los cambios profundos en estructuras centenarias, se abren ante la teoría varias posibilidades de prosecución: intentar entender el camino por el que se ha llegado a la situación actual de proliferación del término "estética», intentar descubrir el carácter ideológico de esta proliferación, también explorar y analizar ante la posibilidad de que el pensamiento (o la falta de pensamiento que se agazapa tras la estetización) no sea más que un reflejo de lo que se llama, no del todo correctamente, «pensamiento débil» e, incluso, existe la posibilidad para la teoría de indicar los factores positivos en esta coyuntura: la posibilidad de esclarecimiento desde la estética de problemas filosóficos y teóricos en general, lo cual implica, como paso previo, el recorrer el primero de los caminos indicados, pues de lo contrario no vemos sitio para salir de un puro decisionismo o irracionalismo al analizar la situación actual. Este último camino es el que nos parece más provechoso: que la realidad del siglo XXI se nos presente estéticamente no es casualidad.

\section{SOBRE LAS «NUEVAS ARTES»}

El término «nuevas artes» connota, sin ninguna intencionalidad, el esquema Artes (las seis clásicas, tradicionales, viejas, las que figuran en los manuales) vs. Nuevas Artes (las que aparecen después, las que no encajan de principio en el anterior esquema y, sobre todo, tienen un componente técnico-tecnológico considerable). Notemos que la expresión «séptimo arte» se introduce en la primera década del siglo XX para referirse al cine, prácticamente en sus inicios, y que supone la primera incorporación a una clasificación que ya en aquél momento se considera canónica, clásica. Las seis artes son escultura, pintura, arquitectura, retórica, música y poesía, si bien existe diversidad en los seis nombres concretos e, incluso, en lo que abarcan dichos nombres?

9 No es éste el tema que pretendemos discutir ahora. Para seguir cronológicamente los avatares de la clasificación de las artes desde la antigüedad lo mejor es consultar la obra ya clá- 
Las «Artes» se sistematizan como tal, esto es: hay motivos que hacen necesaria la sistematización, precisamente en el momento en que entran en crisis, a finales del siglo XIX (han dejado de ser obvias lo que son, que función tienen, que medios pueden utilizar, etc. y debe formalizarse su lugar y destino). En las primeras décadas del siglo XX se inicia propiamente lo que en la terminología actual se llama «arte moderno», que extenderá su dominio hasta el período de los sesenta-setenta del mismo siglo. El arte moderno, como contrapuesto al arte antiguo, el de la sistematización clásica, hará de esa sistematización uno de sus blancos predilectos de crítica en sus obras y escritos ${ }^{10}$. En las décadas de los setenta y ochenta el primer mundo, ahíto ya de consumo, tecnología y desilusionado por las promesas nunca cumplidas, descubre su condición nihilista (avanzada ya más de un siglo antes por el loco del apartado 125 de $L a$ gaya ciencia de Nietzsche) y su solitario pero imparable poder de hacer. Nada puede resistirse a ese poder y, así, toda regla que pudiera aún mantenerse en el campo de la creación artística cae a golpe de nueva inauguración. El arte contemporáneo es eso, la explosión del universo moderno y su vaporización en un continuo de géneros, materiales, temas, formas, etc. que anulan la división misma en arte/s.

Cuando hablamos aquí de «arte contemporáneo» nos referimos al conjunto de propuestas, obras, acciones, etc. que son aceptadas bajo la misma etiqueta de «arte contemporáneo» pese a su disparidad, aunque sólo fuera material. Un modo de abreviar el listado de sub-conjuntos que forman este heterogéneo conjunto del Arte Contemporáneo es referirse a como lo han hecho Instituciones capitales en el mismo Arte Contemporáneo, como el Guggenheim Museum de Nueva York o la Tate Gallery de Londres. El primero, por ejemplo, realiza en su presentación digital una clasificación, necesaria, cuando menos, para presentar sus fondos, en el que el viejo concepto de «Género» se ha substituido por el de «Mediums», siendo estos los siete siguientes: Film/video, Installation, Internet Art, Painting, Photography, Sculpture y Work on paper; igualmente

sica de W. Tatarkiewicz, Historia de seis ideas, tr. F. Rodríguez Martín, Madrid: Tecnos, 1987, cap. II: «El arte: historia de una clasificación». Los ataques de las vanguardias de principios del XX están perfectamente documentados en los textos reunidos en: S. Marchán, F. Calvo y A. González, Escritos de arte de vanguardia, 1900/1945, Madrid: Istmo, 1999, y subrayados en la «Introducción» de los editores, p. 11-15.

10 Conservamos algunas imágenes que sintetizan muchas páginas. Una de ellas es una fotografía (con muy poca definición, casi un dibujo) de Hugo Ball leyendo poesía fonética en el Cabaret Voltaire de Zúrich, en plena explosión de Dadá. Su atuendo, disfraz y demás, los dos atriles y el hecho de que la poesía lo fuera por su sonoridad y no por su significado, escenifican una crítica burlona a preceptos milenarios de las Artes: el artista como demiurgo, la poesía como elevación del alma por las palabras, el público absorto y silencioso, en suma, el Arte como un mundo supra-terrenal. 
se ofrece una clasificación por «Movements», de los cuales se seleccionan 36 para explorar sus colecciones ${ }^{11}$.

De esa explosión de nuevos géneros y, digamos, «estilos» hay un par de características que pueden servirnos para analizar el significado de la propia explosión.

La primera: de los componentes del arte ${ }^{12}$ no hay ninguno que no se haya trastocado, multiplicado, establecido más relaciones, más mediaciones. ¿Qué es lo que nos hace parecer que las antiguas categorías seguirán sirviendo en una situación tan diferente de la original? Creo que lo más razonable es pensar que habrá que someterlas a la misma operación de trastocado, multiplicado y multirelacionado para que vuelvan a servir para la teoría. Tal vez no sea mala precaución metodológica flexibilizar un poco la red para poder pescar en aguas removidas. Si la «imagen del artista ${ }^{13}$ en el arte antiguo responde a tres o cuatro estereotipos, el artista disponía de un catálogo muy limitado de materiales y de herramientas para trabajar ese material (sea oleo, mármol o sonido), vivía en un mundo más pobre, etc. la explosión del arte contemporáneo ha multiplicado por $n$ cada una de las posibilidades anteriores. Pero el molde conceptual sigue siendo el mismo. Tal vez sea esto en lo que pensaba Paul Valery cuando escribió de 1928: «En todo arte hay una parte física que no puede contemplarse ni tratarse como antaño, que no puede sustraerse a las empresas del conocimiento y el poder modernos. Ni la materia, ni el espacio, ni el tiempo son desde hace veinte años lo que eran desde siempre. Hay que esperar que tan grandes novedades transformen toda la técnica de las artes y de ese modo actúen sobre el propio proceso de la invención, llegando quizás a modificar prodigiosamente la idea misma de arte» ${ }^{14}$.

La segunda: podríamos imaginar que por ser el del Arte Antiguo un mundo no precisamente envidiable por sus facilidades materiales para vivir tanto el artista como sus conciudadanos, entonces tendían a esconderlo (el mundo, el material de este mundo), a sublimarlo, de tal forma que en la obra desapareciera (la ilusión de la ilusión, $c f$. teoría ilusionista del arte). Siguiendo una lógica semejante, entonces la abundancia del mundo en el que vive el Arte Contemporáneo provocaría que a la hora de sensibilizar/representar/materializar el mensaje que se quiere transmitir (un mundo [Lebenswelt] que es un no-Mundo [Umwelt], el mundo de sus fantasmas-miedos, de sus fantasías-deseos y de

11 Todo ello puede consultarse en http://www.guggenheimcollection.org/index.html [30/01/2008].

12 Con ello tomamos el significado que le da José Jiménez en su libro Teoría del arte, Madrid: Alianza Editorial/Tecnos 2002, capítulo IV, pp. 105-157.

13 Cf. E. Kris y O. Kurz, La leyenda del artista, tr. P. Vila, Madrid: Cátedra, 1995.

14 P. Valéry, Piezas sobre arte, tr. J.L. Arántegui, Madrid: Visor, 1999, p. 131. 
sus utopías-sueños) lo hiciera mostrando al Mundo, sus cosas, la brocha bien marcada, la pintura plástica, el ruido de la calle como sonido, ... Se trataría de una inversión en el camino que va entre dos mega-conceptos, Material y Espiritual. El arte expresa lo que podría ser nuestro mundo. Para hacerlo «todo vale» con tal de que lo haga. Cualquier cosa puede ser arte. Cualquiera puede ser artista. Estos dos postulados, atribuidos a Joseph Beuys, no son más que la radicalización total y el resultado lógico del principio que actúa en este ámbito: libertad. Libertad creativa, libertad interpretativa, libertad valorativa, libertad crítica. No vale ni el color de la sangre ni el peso de la bolsa.

En esta situación de libertad casi total, se puede esperar que haya tantos significados diferentes de las categorías estéticas como individuos existan. Parece obvio que podría ser imposible pretender contener esta marea, poder contar con un vocabulario estético más o menos común. Por tanto, en el estudio de las nuevas artes podemos poner en un segundo plano lo que se refiera a categorías que no permitan una clasificación abierta, ambigüedad también podría decirse, aunque ésta sólo se referiría, si imaginamos un diagrama de Venn, a los bordes exteriores del conjunto de elementos que abraza la categoría. La categoría «Arte» podría ser la primera en ser pasada por este filtro.

En la génesis de la «explosión» (semejante a la de una Supernova en el hecho de que da origen a nuevos universos) que está en el origen a la situación actual podemos distinguir entre elementos endógenos al mundo del arte y motivos exógenos a él. Aunque esta distinción requeriría muchos matices, simplemente pretendemos distinguir entre el grupo de las personas vinculadas de alguna manera a la vida artística y el grupo de las personas totalmente ajenas.

La búsqueda de causa internas puede seguirse de la mano del trabajo de dos de los críticos de arte más influyentes de la segunda mitad del siglo XX: Clement Greenberg ${ }^{15}$ y Harold Rosenberg ${ }^{16}$. Estos críticos plantean cuestiones teóricas acerca del arte que se está haciendo en aquél momento valorando entre posiciones alternativas pero ambas internas, del propio lenguaje o grupo: el «mundo del arte». Discurren los desarrollos de las discusiones por dos vías fundamentales: 1) de principio un intentar regirse por las normas inmanentes al propio arte, esto es, una radicalización de los principios modernistas de que el arte se autojustifica, se autoexpone, se autoexplica, etc. (esto es: toda la ideología modernista que, andando el tiempo, estará pendiendo, como espada de Damocles, sobre el arte contemporáneo) y 2) justificar una determinada

$15 C f$. C. Greenberg, Arte y cultura: ensayos críticos, tr. J. Beramendi y D. Gamper, Barcelona: Paidós, 2002.

$16 C f$. H. Rosenberg, The Tradition of the New, Nueva York: Horizon Press, 1959. 
concepción del hecho artístico promoviendo discursos enmarcables en la teoría estética filosófica, sean esos discursos los del expresionismo abstracto, del minimalismo, del arte conceptual o del que sea.

Exógenos: Esto es, obtenidos a partir de la evolución del contexto en el que hay arte. Este contexto incluye los medios, las técnicas, los posibles lenguajes, etc. que llevan a la producción de las obras, tanto como a la evolución de los medios, los espacios, los estereotipos, las Imágenes-modelo, etc. que actúan en la recepción de estas obras. Especialmente significativo para el caso es que a partir de la misma época (sesenta-setenta del siglo XX) se produce la gran explosión de los medios de comunicación de masas, de la sociedad de consumo (y de consumo cultural), del turismo de masas, de la posibilidad técnica de crear, reproducir, transmitir, archivar, cualquier cosa, etc.

Todo ello nos lleva a pensar que para tratar teóricamente el conjunto de lo que hoy denominamos «nuevas artes», es necesaria una reformulación de las categorías estéticas atendiendo a dos procesos característicos de la época (la nuestra) en que se dan estas artes: la tecnificación de los medios, procesos, etc. y la masificación de los productores, transmisores y receptores.

Tecnificación: Por primera vez (tal vez sea exagerado esto objetivamente, pero al menos funciona según la comprensión habitual de la Historia del Arte) los medios materiales están en primer plano, y no el espiritualismo creador.

Masificación: por primera vez los sujetos del mundo estético no son una minoría minoritaria, sino la totalidad de los habitantes del planeta.

Conclusión: es hora de tomar en serio lo que Paul Valéry escribió hace 80 años y, para hacerlo, tomar el programa de Benjamin de 1936 para desarrollar las quince tesis, una por epígrafe de su texto, que aún hoy necesitan desarrollarse. El programa estético contenido en «La obra de arte en la época de su reproductibilidad técnica» es, posiblemente, el primero en plantearse a partir de la constatación de los procesos de tecnificación y masificación como substanciales de nuestra época.

\section{CODA}

Lo que se deriva del punto 1 es la necesidad de enfocar el trabajo filosófico no hacia la prescripción (cualquiera que sea la forma que adquiera), sino hacia la crítica de la «progresividad» o no de las propuestas estéticas. Progresividad que debe referirse al criterio de «libertad (expresiva)», lo contrario de «consumo cultural».

Lo que se deriva del punto 2 es la necesidad de flexibilizar los conceptos que nos sirven para tratar el proceso de producción y recepción estética para poder así recalcar las formas de la experiencia estética y no tanto los procedimientos seguidos para llegar a esta experiencia. 
La categorización estética heredada de la época clásica de constitución de la estética filosófica, de Baumgarten a Hegel, posiblemente han perdido mucho de su potencia explicativa. Sea por la erosión temporal de las categorías mismas, sea por las enormes transformaciones del contexto en que dichas categorías han de operar. En todo caso es el punto desde el que procedemos al análisis el que se ha transformado. Las categorías heredadas del clasicismo estético europeo se basan en (parten del presupuesto de la centralidad para la comprensión teórica de) la intencionalidad de un sujeto. Intención, el querer hacer, la expresión (expresividad) estética: en su nombre se han producido casi todas las revueltas artísticas contra los cánones anteriormente establecidos. Las que deben surgir para dar cuenta de las «nuevas artes» transformarían lo anterior según un nuevo principio: máxima potencia expresiva (a eso ayudan las nuevas artes) para hacernos lo más independientes posible de lo material, lo físico, lo indeterminable (en definitiva, lo no-humano). El objeto de la estética sería entonces la concreción (construcción) individual particular de una Imagen colectiva fabricada directamente por el mundo audiovisual: este podría ser el programa de una estética en tiempos de cultura audiovisual. 